\title{
Abundance, Size Distribution and Reproductive Biology of Female Mud Crab (Scylla olivacea) From Sundarbans Mangrove Forest in the Southwest Coastal Region of Bangladesh
}

\section{Islam MS*, Mondal A, Khan Y and Kader A}

Department of Fisheries \& Marine Bioscience, Jashore University of Science \& Technology, Bangladesh

*Corresponding author: Islam MS, Professor, Department of Fisheries and Marine Bioscience, Jashore University of Science and Technology, Jashore-7408, Bangladesh, Email: dms.islam@ just.edu.bd

\section{Research Article \\ Volume 4 Issue 2}

Received Date: April 15, 2020

Published Date: May 04, 2020

DOI: $10.23880 /$ ijoac-16000186

\section{Abstract}

The mud crab (Scylla olivacea) is one of the important exported commodities and playing a vital role in the economy of Bangladesh. The harvesting and exportation of crab increasing day by day without knowing the abundance and biological traits particularly of female mud crab. The present study was taken to assess the abundance, size distribution, population distribution regarding physiochemical properties and reproductive biology of female mud crab from selected Sundarbans mangrove forest in the southwest Bangladesh. The year-round female mud crab samples were taken from different stations of Koyra of Khulna and Symnagor of Satkhira district. The results showed that female crab harvested almost in similar pattern from both sampling areas. The average abundance estimated as $4.9 \pm 1.4(\mathrm{~kg} /$ day/collector) with the average number of 15.5 \pm 2.9 /day/collector. The assessed samples was $33 \%$ female and $15 \%$ hijra (immature female) reported from Koyra, Khulna while only $10 \%$ female and $44 \%$ hijra reported from Symnagor, Satkhira. The water parameters like salinity, pH, temperature, total dissolve solids, dissolve oxygen and conductivity were measured in each sampling months from different sampling stations and were not significant difference $(\mathrm{P}>0.05)$ between two districts. In addition, there is no significant relationship between abundance and recruitment of female crabs with the major physiochemical parameters. However, hijra crab was higher in number during winter in Symnagor, Satkhira. In case of size-class distribution, it is noticed that most female species (35\%) were belong to the size group of $80-89 \mathrm{~mm}$ internal carapace width (ICW). Almost $90 \%$ female crabs were belonging to the size $<90 \mathrm{~mm}$ ICW. Ovarian development stages were categorized into five stages like I) immature ovary, II) under develop, III) early develop, IV) late develop and V) mature stage according to their internal observation of ovaries. There were only $14 \%$ individuals belongs to the mature ovarian development stage. However, $56 \%$ sampled individuals were mature considering the formation of vitellogenesis (ovarian development stage III-V). The $50 \%$ of female individuals get mature at the size of $84.63 \mathrm{~mm}$ ICW. The present findings will be act as base line to propose suitable management strategies of the resources in the coastal area of Bangladesh.

Keywords: Scylla olivacea; Abundance; Size-Class Distribution; Ovarian Development Stages; Water Parameters; Female Maturity Size 
Abbreviations: ICW: Internal Carapace Width; TDS: Total Dissolved Solid; DO: Dissolved Oxygen; SD: Standard Deviation.

\section{Introduction}

Mud crab fishing has been accomplished for many years in coastal region in Bangladesh, particularly in southwest region of Bangladesh. The fishing based principally on capture and fattening of juvenile crabs from the wild. Export of mud crab started in 1977-78, and became a constant trade in 1982. The export of live mud crabs from Bangladesh has increased many folds in the last decade [1]. The export of mud crab presently ranked third among frozen foods exported from Bangladesh [2]. Annual crab production from Bangladesh is about 10,000 Ton which market price is about Tk. 350 crore. There were $60 \%$ of exported mud crab of the country is coming from the mangrove forests of the Sundarbans [3]. However, major production is coming from southwestern (covering Khulna, Satkhira and Bagherhat districts) region which earning about Tk. 200 crore each year.

Though increasing export of the item, gaining popularity in locality, the mud crab fishery in Bangladesh is still understudied, with a very little information on population status, abundance, distribution pattern with physiochemical properties, biological traits etc. Like in other Asian countries, it was believe that the natural mud crab populations are declining due to (i) over-exploitation, (ii) loss of mangrove habitat, and (iii) coastal environmental degradation. It is noticed that $>80 \%$ mud crab are being caught before getting the size of first maturity in Thailand [4]. To conserve the mud crab stock some countries already have imposed minimum landing size [5].

The information on the habitat use in different life stages and sexes is very important for the management. In addition, distribution of mud crab on the basis of physiochemical properties is also key feature to establish the proper management protocol of the mud crab population. Adult mud crabs generally inhabit muddy estuaries and enclosures in mangrove ecosystems that are influenced by tidal waters $[6,7]$. They prefer different salinity and temperature range in different stages of life. The optimum salinities and temperature for mud crab is of $25-30 \mathrm{ppt}$ and of $26-30^{\circ} \mathrm{C}$ respectively [8-10]. Juvenile prefer protected area from large aquatic predators; upper intertidal area between Pneumatophores of Avicennia marina near the mangrove fringe [11]. Female crabs prefer to bury in the mud than seeking shelter in burrows, so the majority of crabs found in burrows are males [12,13].
The individual size and relative abundance (catch per unit effort) of mud crab have decreased in recent years according to local fishermen. In 2018, Chakraborty, et al. [14] confirmed the noticeable decline in abundance of mud crab in coastal area of Bangladesh. In addition, harvesting of small-size crab due to fattening practice is also preventing the reproduction of the species. Last few catastrophic natural disasters (like Aila, Sidre) have changed livelihood pattern and many of them engaging in mud crab harvesting which also exaggerating the threats of the wild population. In-situ surveys of the female mud crab abundance and their size distribution and the population distribution in relation to the physiochemical properties have not been conducted in Bangladesh to date. Thus, there is no baseline information on the female abundance of the local female mud crab population which can say whether can regenerated their original stock. In addition, to set fruitful management strategies, it is essential to know the details biology such as size-class distribution, ovarian development stages, maturity size, etc of the female crabs which is lack in the locality.

The present study has been conducted to assess the abundance (catch per unit effort), size class distribution, and reproductive biology of female mud crab (S. olivacea) in the different location of the south-west coastal region of Bangladesh. In addition, major water parameters were measured to find out any relationship with female crab distribution or with their recruitment. Thus, the present research will be act as the baseline information for the management of the female mud crab fishery.

\section{Materials and Methods}

\section{Study Area and Plan of Works}

Year-round monthly samples were collected (November 2018 to November 2019) from Sundarbans mangrove forest associated southwestern coastal districts of Bangladesh. Mud crab samples were collected from major two mangrove associated sub-districts such as Koyra of Khulna district and Symnagor of Satkhira district (Figure 1). There were three sampling stations such as Munshigonj, Kodomtala and Nildumur of Symnagor, Satkhira district and two stations like Katkata, and Dokkhin Bedkashi of Koyra, Khulna district. These sampling stations cover different rivers across the Sundarbans like Rai and Kopotaskma of Koyra and Chuna, Malancha and Kakshali of Symnagor, Satkhira. The two-broad area of research like assessment of relative abundance of mud crab in the field and biological works at the laboratory were conducted. The laboratory activities were performed in the laboratory of Fisheries and Marine Bioscience, Jashore University of Science and Technology, Jashore, Bangladesh. 


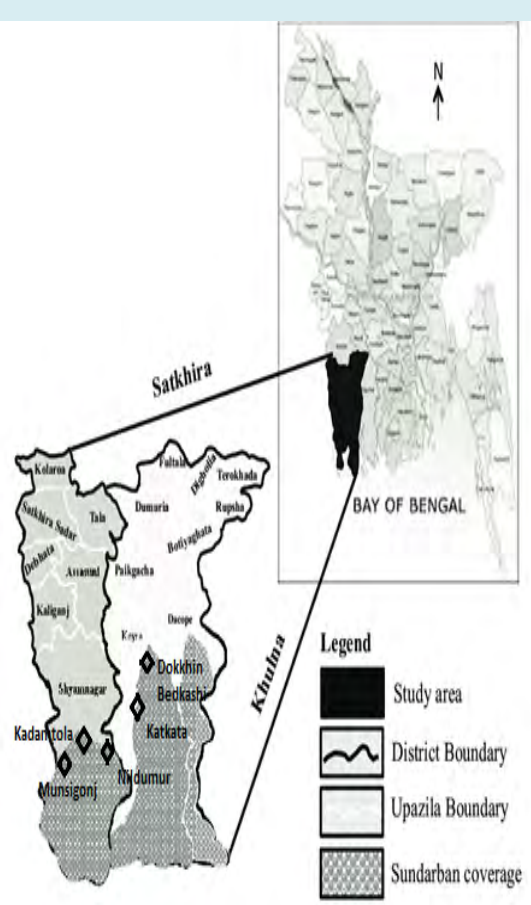

Figure 1: The map showing the two coastal districts of South-western Bangladesh. The diamond $(0)$ shape indicated the specific location of sampling. Picture adopted from Abedin and Shaw [15].

\section{Collection of Samples}

Mud crabs were harvested directly in-situ using a fixed long line gear from selected sampling sites. Samples were taken directly from selected crab collector who used the long line gears from each station for a period of one year. However, samples were not taken during January and February due to Government restriction (actually government restriction period December to February) on mud crab harvesting. In addition, during March also could not possible due to restriction of fishing within mangrove area for the management of hilsa fishery. The selected crab collectors were trained up earlier how to collect, record and preserved for the further study.

\section{Sexes of Mud Crab}

The sexes were determined at the field level mainly followed their abdominal flap. Male have slim inverse ' $V$ ' shape while female have inverse ' $U$ ' shape abdomen along with large strong claw in male (Figures 2a, 2b). However, in locally harvester treated one more category of sex, called hijra (hermaphrodite). Actually, they are immature female or female before pubertal molt which abdominal flap shape nearly look alike male (Figure 2c). To get precise information from the harvester, in the present study, they treated as hijra. The harvested female crabs were transferred to the laboratory for further study.

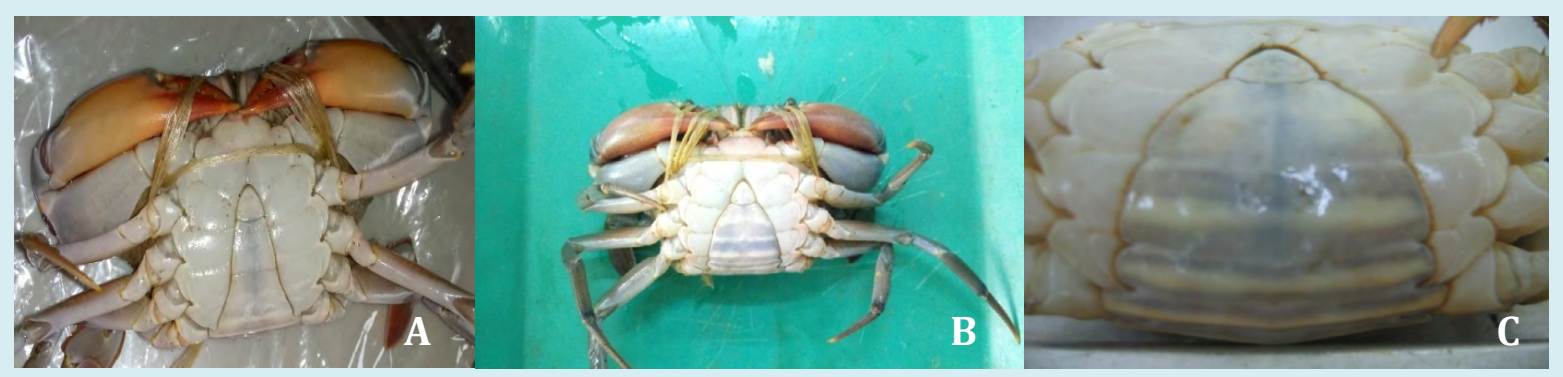

Figure 2: The different sexes of mud crab collected from southwestern coastal region of Bangladesh. Male (a), female (b) and hijra (hermaphrodite) (c) crab according to local fishers. 


\section{Assessment of Abundance and Assemblage Pattern}

At each station, the relative abundance (catch per unit of effort, CPUE) of female crabs was estimated in term of number of crabs caught per long line. Six collectors from each sub-district were selected to estimate the CPUE. Each collector uses a single long-line gear of about $450 \mathrm{~m}$ long with about 250 baits. At each station, CPUE was estimated in terms of number of female crabs (including hijra) caught per long line in a single day effort. The assemblage pattern of female crabs like abundance and size distribution were developed in accordance to major water parameters in the study area.

\section{Measurement of Samples}

The internal carapace width (ICW) and total body weight (BW) of the female crab were measured to the nearest $0.1 \mathrm{~cm}$ and to the nearest $0.5 \mathrm{~g}$ using a slide calipers and weighing balance (A\&D company, Model: EK 1200i; Made in Japan), respectively (Figures $3 \mathrm{a}$ and $3 \mathrm{~b}$ ).

\section{Size Structure Determination}

The collected specimens were divided into six classes according to $10 \mathrm{~mm}$ intervals from $60 \mathrm{~mm}$ to $120 \mathrm{~mm}$ for the size structure determination.

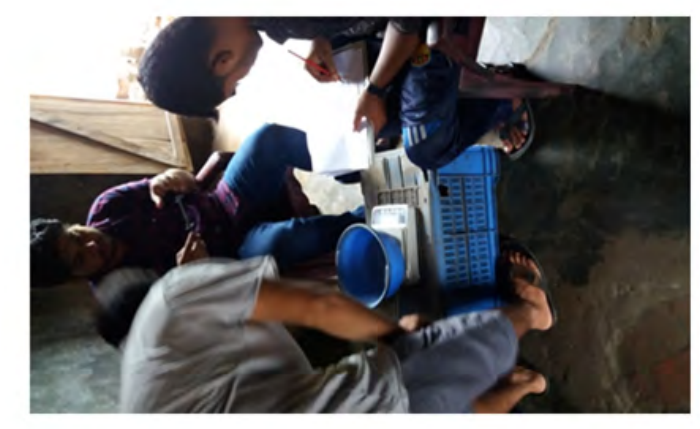

(a)

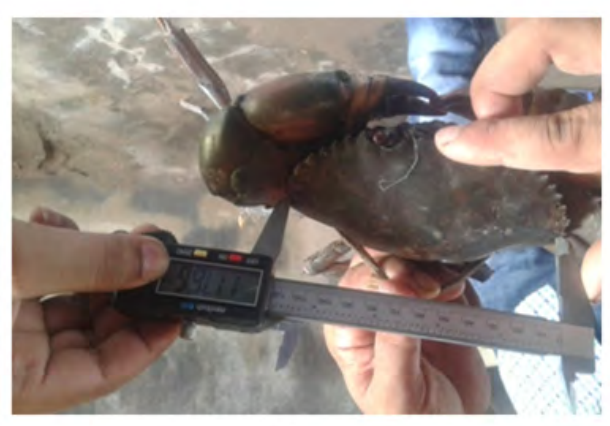

(b)

Figure 3: In-situ measurement of individual body weight (g) (a) and internal carapace width (mm) (b) of mud crab, Scylla olivacea from southwestern coastal region of Bangladesh.

\section{Measurement of Water Parameters}

The water parameters such as dissolved oxygen (D0), $\mathrm{pH}$, water temperature and salinity were measured in each sampling time from each station for a period of one year. A pH meter (EZo DO; Model-7200; Made in Taiwan) was used for the measurement of $\mathrm{pH}$ and temperature; a DO meter (LT Lutron; Model- YK-22 D0; Made in Taiwan) was used for the measurement of DO. Salinity was measured with a portable refractometer (Model: ATO-CRM-010). TDS and conductivity were measured using TDS meter (Hanna Instruments HI98301 DiST1 EC \& TDS Tester 2000PPM).

\section{Observation of Ovarian Stage}

The female with mature abdomen shape (inverse U-shape) were separated and assessed to observe the ovarian condition according to the characteristics of the ovary. The progresses of ovarian maturation were classified into five different stages based on external characters [16]. The immature ovary (Stage I) is a threat like structure which is transparent color and sometimes difficult to recognize and separate from the digestive gland. The under developing ovary (stage II) form lines on the upper portion of digestive gland and was easily differentiated from the gland and it showed creamy white to white coloration. The early developing ovary stage (stage III) changes to yellow color. The late-developing stage (Stage IV), the lobules were developed prominently in sterno carapace and defined as deep yellow or light orange coloration of ovary. In the mature stage (Stage V), the ovary enlarged to the maximum and eventually covered the hepatopancreas and the majority of the cardiac stomach. In this stage, the ovary is deep orange in color.

\section{Determination of Maturity Size}

Females with vitellogenic ovaries were considered to be mature individuals (the ovarian developmental stages III-V). To estimate the size at first maturity, the minimum size at which the female attains a vitellogenic ovary was recorded through the histological observation of ovaries for Scylla olivacea. The probit scale was applied to determine the size at which $50 \%$ of females reach sexual maturity (ICW50) [5]. 
The data from sample crabs will be allocated to $10-\mathrm{mm}$ ICW size classes.

\section{Data Analysis}

Regression analysis was performed to determine the relation of female abundance (number and $\mathrm{kg} / \mathrm{day} /$ effort) with selective water parameters (Salinity and water temperature). The statistical t-test was used to determine the significance of variation among the different stations (districts) average. A significant level of $P>0.05$ was considered.

\section{Results}

\section{Relative Abundance}

The average female crab catch $(\mathrm{kg} /$ day) and average number of crab harvesting (day/fishermen) at Koyra, Khulna and Symnagor of Satkhira district is presented in Table 1. The number of female crab catch was significantly $(P>0.05)$ higher in Symnagor area than Koyra but not the biomass. The average catch/day/collector during different sampling months from Koyra and Symnagor are presented in Figure 4 and Figure 5 respectively.

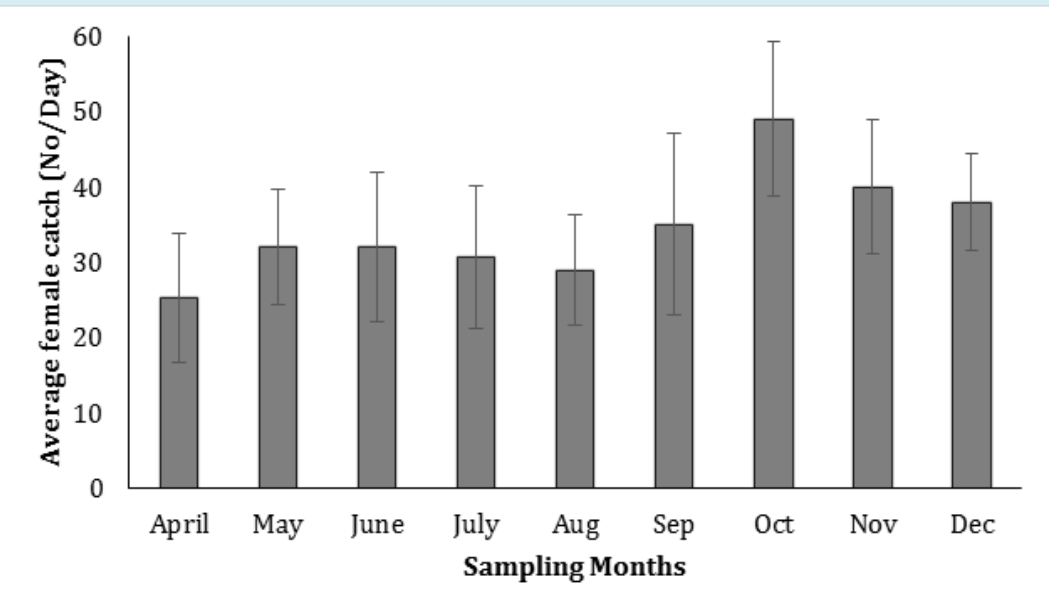

Figure 4: The average female mud crab catch (number/day/collector) from Koyra, Khulna in different sampling months.

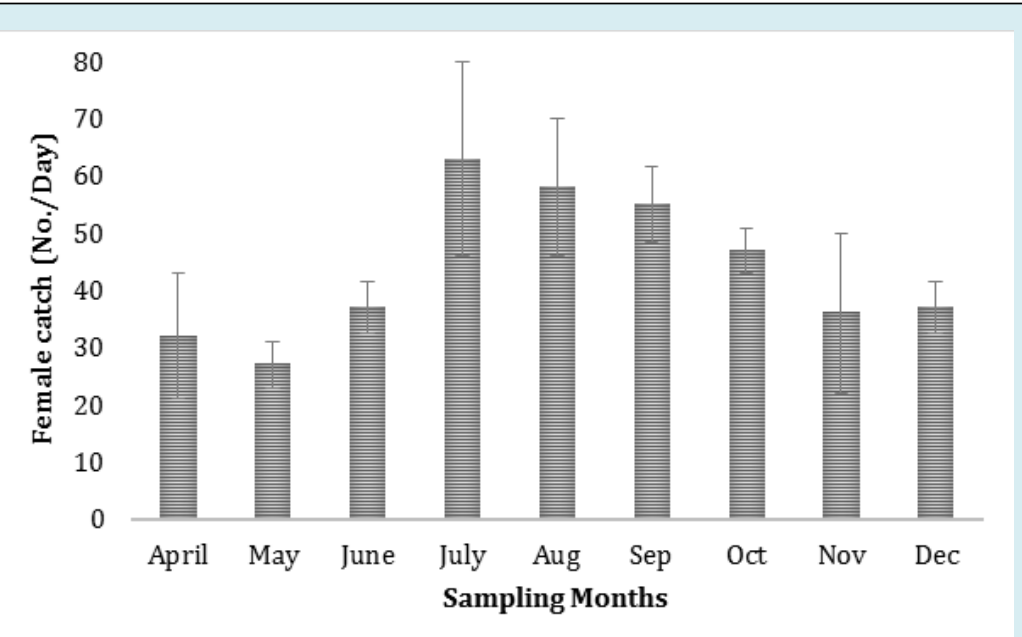

Figure 5: The average mud crab female catch (number/day/collector) from Symnagor, Satkhira in different sampling months.

The female catch was higher in number (44crabs/day/ collector) in Symnagor than Koyra. However, the hijra crab (immature female) was much higher in Symnagor area than the Koyra. The female crab was 33\% while only 15\% hijra reported from Koyra, Khulna whereas only 10\% female and 44\% hijra reported from Symnagor, Satkhira (Figures 5 \& 6). So, we may say that immature crabs (hijra) are more available i.e. recruited in the Satkhira region than Koyra. 


\begin{tabular}{|c|c|c|}
\hline Sampling Station & Ave catch $(\mathbf{k g} /$ day) \pm SD & Ave catch (No/day/Collector) \pm SD \\
\hline Koyra, Khulna & $5.8 \pm 1.1$ & $35.0 \pm 9.0$ \\
\hline Symnagor, Satkhira & $5.6 \pm 2.4$ & $44.0 \pm 8.6$ \\
\hline Average & $\mathbf{5 . 7 \pm 1 . 8}$ & $\mathbf{3 9 . 5 5 \pm \mathbf { 8 . 8 }}$ \\
\hline
\end{tabular}

Table 1: The average catch (kg/day) and average number of female crab fishing (day/fishermen) from two coastal sub-districts of Koyra, Khulna and Symnagor, Sathkhira district.
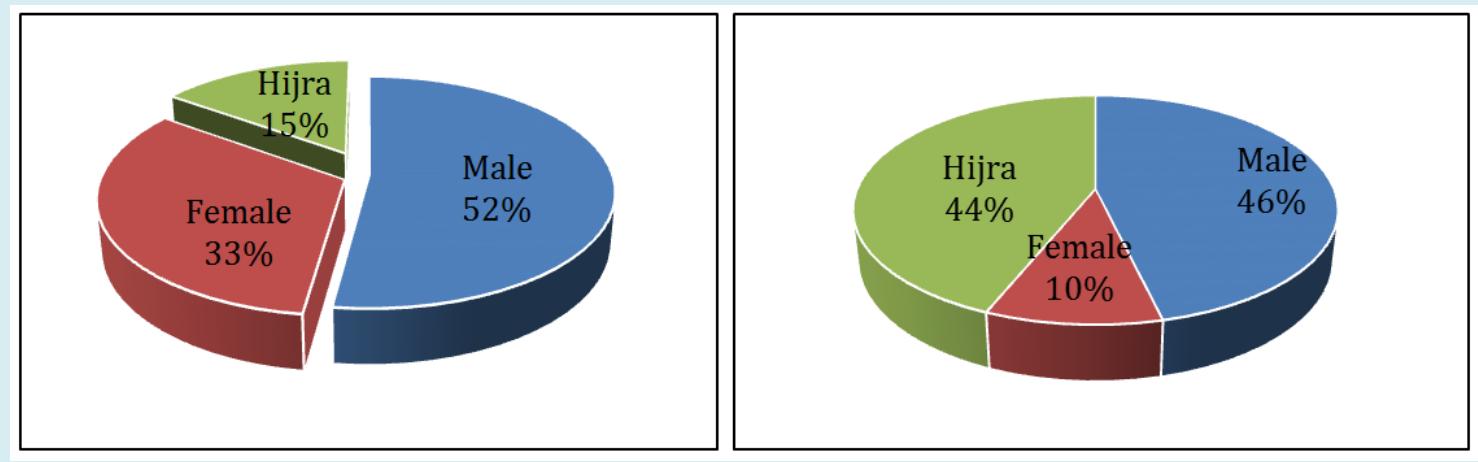

Figure 6: The sex composition of mud crabs collected during sampling time from two coastal sub-districts of southwestern Bangladesh, Koyra of Khulna and Symnagor of Satkhira district.

\section{Physiochemical Parameters}

The mean values of the water quality parameters like salinity, $\mathrm{pH}$, temperature, dissolve oxygen (DO), total dissolve solids (TDS), and conductivity with standard deviation (SD) in the two coastal districts (Khulna and Satkhira) are shown in Table 2 and Table 3 respectively. During the study period, the maximum salinity $17.2 \mathrm{ppt}$ recorded in April and the minimum (5.2 ppt) was in October in the sampling station, Koyra, Khulna. The maximum water temperature of $33.8^{\circ} \mathrm{C}$ and the minimum $\left(24.5^{\circ} \mathrm{C}\right)$ recorded in Koyra, Khulna and Symnagor, Satkhira respectively.

\begin{tabular}{|c|c|c|c|c|c|c|}
\hline Sampling month & Salinity (ppt) & $\mathbf{p H}$ & Temperature $\left({ }^{\circ} \mathbf{C}\right)$ & $\mathbf{D O}(\mathbf{m g} / \mathbf{L})$ & TDS (mg/L) & Conductivity (mS/cm) \\
\hline April & $17.2 \pm 0.3$ & $7.0 \pm 0.2$ & $33.8 \pm 0.4$ & $6.9 \pm 0.3$ & $17000.0 \pm 424$ & $19.0 \pm 0.4$ \\
\hline May & $16.4 \pm 0.1$ & $6.8 \pm 0.1$ & $33.6 \pm 0.2$ & $7.1 \pm 0.4$ & $17300.0 \pm 283$ & $19.0 \pm 0.7$ \\
\hline June & $16.4 \pm 0.5$ & $6.9 \pm 0.1$ & $33.2 \pm 0.1$ & $7.2 \pm 0.5$ & $17600.0 \pm 424$ & $18.8 \pm 1.4$ \\
\hline July & $14.3 \pm 1.0$ & $6.9 \pm 1.1$ & $33.0 \pm 0.7$ & $7.3 \pm 0.5$ & $18700.0 \pm 1131$ & $23.0 \pm 5.9$ \\
\hline Aug & $11.9 \pm 2.9$ & $6.6 \pm 0.1$ & $30.3 \pm 2.3$ & $6.9 \pm 1.0$ & $15695.0 \pm 3825$ & $24.0 \pm 6.1$ \\
\hline Sep & $9.0 \pm 2.1$ & $9.0 \pm 0.1$ & $32.3 \pm 1.8$ & $8.3 \pm 0.4$ & $11925.0 \pm 2793$ & $18.6 \pm 5.0$ \\
\hline Oct & $5.2 \pm 0.2$ & $7.7 \pm 0.1$ & $30.4 \pm 0.5$ & $6.4 \pm 0.4$ & $6895.0 \pm 233$ & $10.4 \pm 0.3$ \\
\hline Nov & $5.9 \pm 0.4$ & $7.4 \pm 0.3$ & $27.4 \pm 0.2$ & $8.3 \pm 0.2$ & $8650.0 \pm 1131$ & $13.1 \pm 0.9$ \\
\hline Dec & $7.1 \pm 1.2$ & $7.2 \pm 1.0$ & $26.7 \pm 0.2$ & $9.6 \pm 0.4$ & $9310.0 \pm 1513$ & $14.1 \pm 2.3$ \\
\hline
\end{tabular}

Table 2: Mean values (mean \pm SD) of water parameters (salinity, $\mathrm{pH}$, Temperature, DO, TDS and conductivity) recorded during sampling times from Koyra, Khulna.

\begin{tabular}{|c|c|c|c|c|c|c|}
\hline Sampling month & Salinity (ppt) & $\mathbf{p H}$ & Temperature $\left({ }^{\circ} \mathbf{C}\right)$ & $\mathbf{D O}(\mathbf{m g} / \mathbf{L})$ & TDS (mg/L) & Conductivity (mS/cm) \\
\hline April & $17.2 \pm 0.3$ & $7.0 \pm 0.2$ & $33.6 \pm 0.6$ & $6.9 \pm 0.3$ & $17000.0 \pm 424$ & $19.0 \pm 0.4$ \\
\hline May & $16.5 \pm 0.2$ & $6.7 \pm 0.0$ & $33.1 \pm 0.5$ & $6.7 \pm 0.2$ & $16920.0 \pm 820$ & $19.1 \pm 0.5$ \\
\hline June & $16.1 \pm 0.1$ & $6.8 \pm 0.0$ & $32.8 \pm 0.6$ & $6.8 \pm 0.1$ & $16820.0 \pm 679$ & $18.1 \pm 0.4$ \\
\hline
\end{tabular}




\begin{tabular}{|c|c|c|c|c|c|c|}
\hline July & $14.3 \pm 1.1$ & $6.4 \pm 0.4$ & $32.8 \pm 1.0$ & $6.8 \pm 0.1$ & $18500.0 \pm 1414$ & $18.5 \pm 0.5$ \\
\hline Aug & $13.2 \pm 1.1$ & $6.8 \pm 0.1$ & $30.6 \pm 1.8$ & $6.6 \pm 0.6$ & $17350.0 \pm 1485$ & $26.6 \pm 2.5$ \\
\hline Sep & $10.3 \pm 0.4$ & $9.0 \pm 0.1$ & $32.8 \pm 1.1$ & $7.4 \pm 0.8$ & $13600.0 \pm 424$ & $21.1 \pm 1.6$ \\
\hline Oct & $6.5 \pm 1.6$ & $7.6 \pm 0.0$ & $31.3 \pm 1.8$ & $7.2 \pm 0.6$ & $8570.0 \pm 2135$ & $12.9 \pm 3.3$ \\
\hline Nov & $6.1 \pm 0.0$ & $7.4 \pm 0.2$ & $27.4 \pm 0.2$ & $7.8 \pm 0.8$ & $9780.0 \pm 467$ & $13.6 \pm 0.2$ \\
\hline Dec & $6.7 \pm 1.6$ & $7.1 \pm 0.7$ & $24.5 \pm 2.9$ & $8.8 \pm 0.9$ & $8875.0 \pm 2128$ & $13.5 \pm 3.2$ \\
\hline
\end{tabular}

Table 3: Mean values (mean \pm SD) of water parameters (salinity, $\mathrm{pH}$, Temperature, DO, TDS and conductivity) recorded during sampling times from Symnagor, Satkhira.

\section{Water Parameters and Relative Female Abundance}

It is noticed that there was no such strong correlation of female abundance with water salinity and temperature in both districts (Figures 7 \& 8). However, female abundance increased from July particularly in Symnagor area while salinity goes down. In addition, if we consider the hijra crab (immature female; new recruitment), it was noticed no such relation with water temperature and salinity in Koyra, Khulna (Figure 9). However, strong inverse relation noticed between water salinity and abundance of hijra crab from Symnagor, Satkhira (Figure 10).

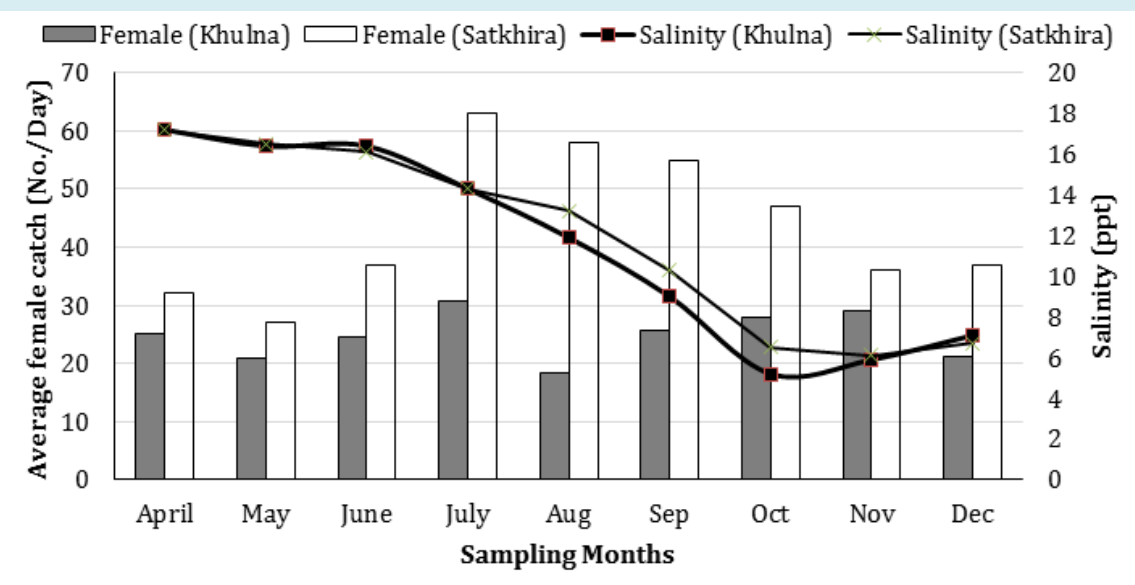

Figure 7: The relationship of water salinity and female mud crab (average catch in number) during the sampling period from Koyra, Khulna and Symnagor, Satkhira.

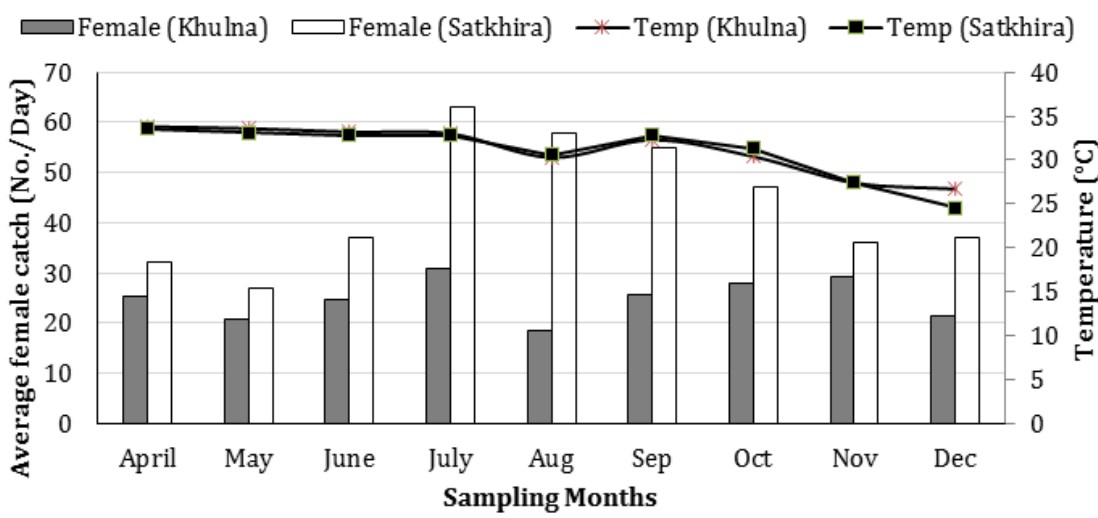

Figure 8: The relationship of water temperature and female mud crab (average catch in number) during the sampling period from Koyra, Khulna and Symnagor, Satkhira. 


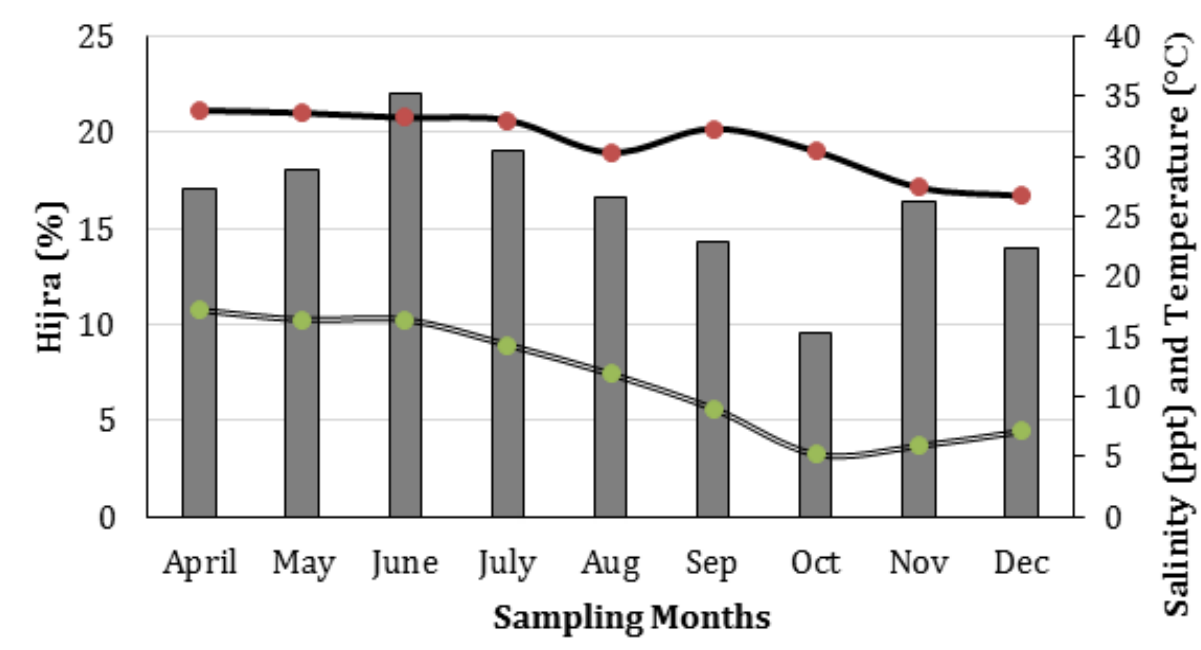

$\square$ Hijra (\%) $\quad \longrightarrow$ Temperature $\quad \leadsto$ Salinity

Figure 9: The abundance (\%) of hijra crab (considered as newly recruitment of female crab) regarding water temperature and salinity during the sampling period from Koyra, Khulna.

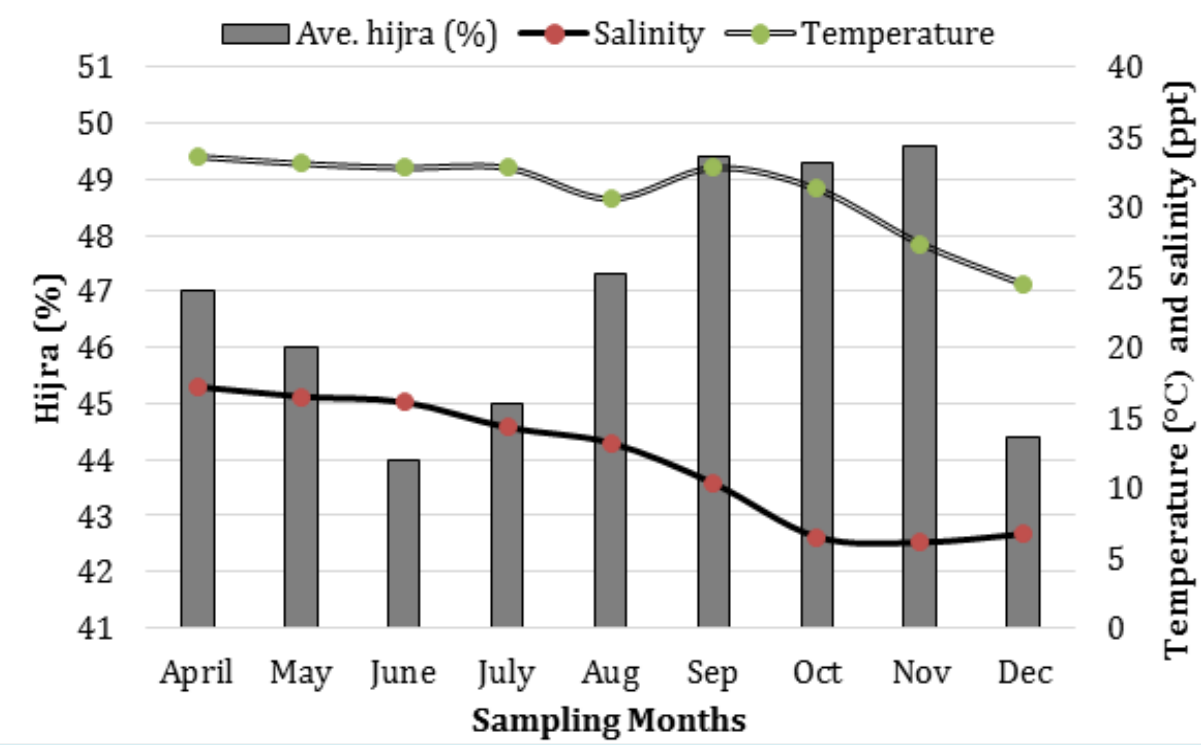

Figure 10: The abundance of hijra crab regarding water temperature and salinity during the sampling period from Symnagor, Satkhira.

\section{Reproductive Biology}

Size-class distribution: In case of size-class distribution, it is noticed that the size distribution of female crabs were almost similar pattern in both size and weight class distribution in two sampling districts (Figures $11 \& 12$ ). The average size was $76.4 \mathrm{~mm}$ internal carapace width (ICW) and 99.33 g body weight (BW) from the samples of Koyra, Khulna whereas $78.6 \mathrm{~mm}$ ICW and $103.71 \mathrm{~g}$ BW from the area of Symnagor, Satkhira. The most female individuals (33\%) were belong to the size group 80-89 $\mathrm{mm}$ ICW from the study area Koyra, Khulna and almost $90 \%$ female crabs were belonging to the size $<90 \mathrm{~mm}$ ICW. Whilst, the major 
group also noticed within the size group 80-89 mm ICW from Symnagor, Satkhira where $36 \%$ female was under that size group. However, smaller size crab $(<60 \mathrm{~mm}$ ICW) were higher in percentage in Koyra, Khulna area compare to other district (Figure 11). The most individuals were under the weight class 50-100 g. However, very few female crabs $>200 \mathrm{~g}$ noticed in Koyra while none from Symnagor.

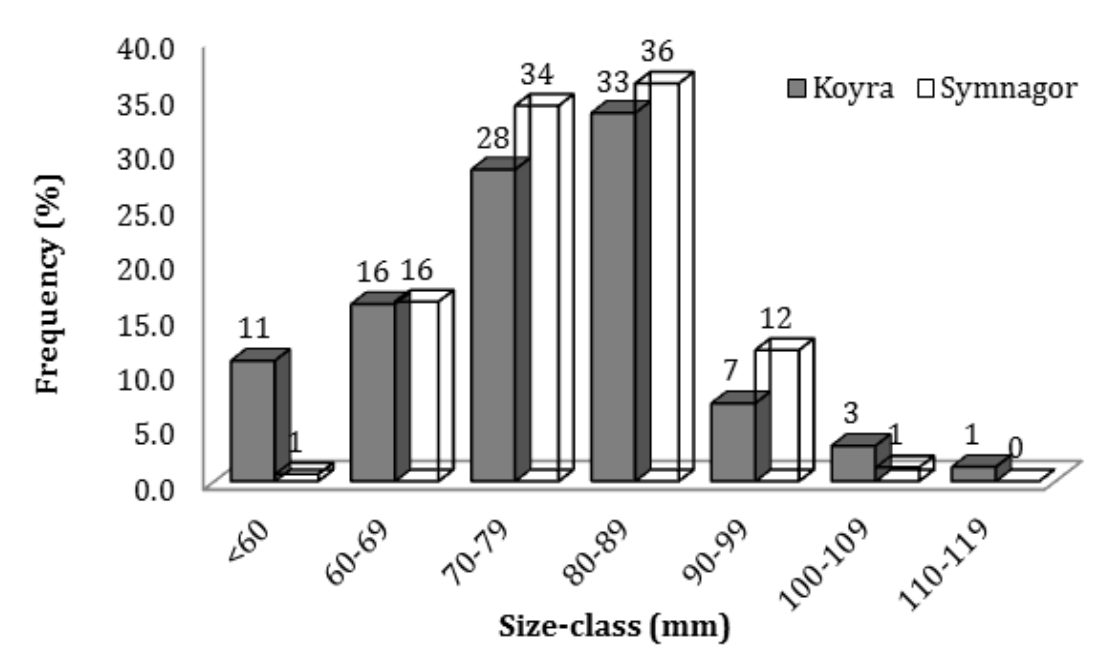

Figure 11: The size-class $(\mathrm{mm})$ distribution of female mud crab S. olivacea collected from two coastal sub-districts of Bangladesh, Koyra, Khulna and Symnagor, Satkhira.

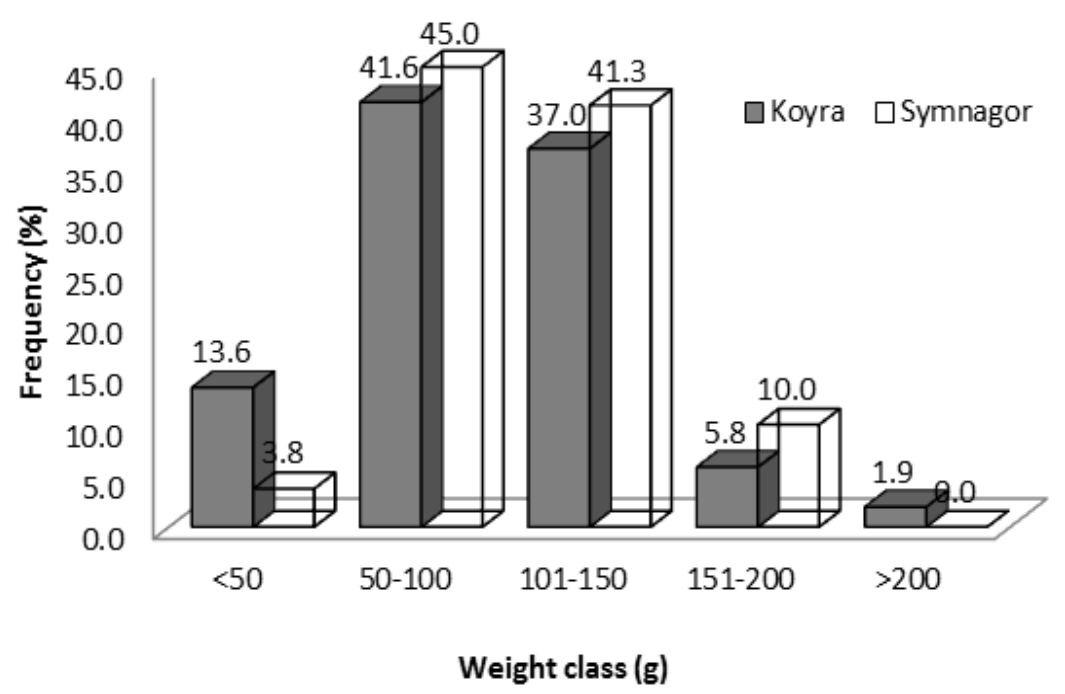

Figure 12: The weight-class $(\mathrm{mm})$ distribution of female mud crab S. olivacea collected from two coastal sub-districts of Bangladesh, Koyra, Khulna and Symnagor, Satkhira.

Ovarian development: In the present study, it was showed that $9 \%$ and $19 \%$ individuals were maturation stage (stage V) and most of the individuals (34\% and 26\%) were under the maturation stage-I, i.e. immature ovary in Koyra, Khulna and Symnagor, Satkhira respectively. However, if we consider, from the vitellogenesis i.e. from the stage III-V, as the maturation of ovary, $54 \%$ and $58 \%$ of individuals were mature from two districts respectively (Figures 13a and 13b). 


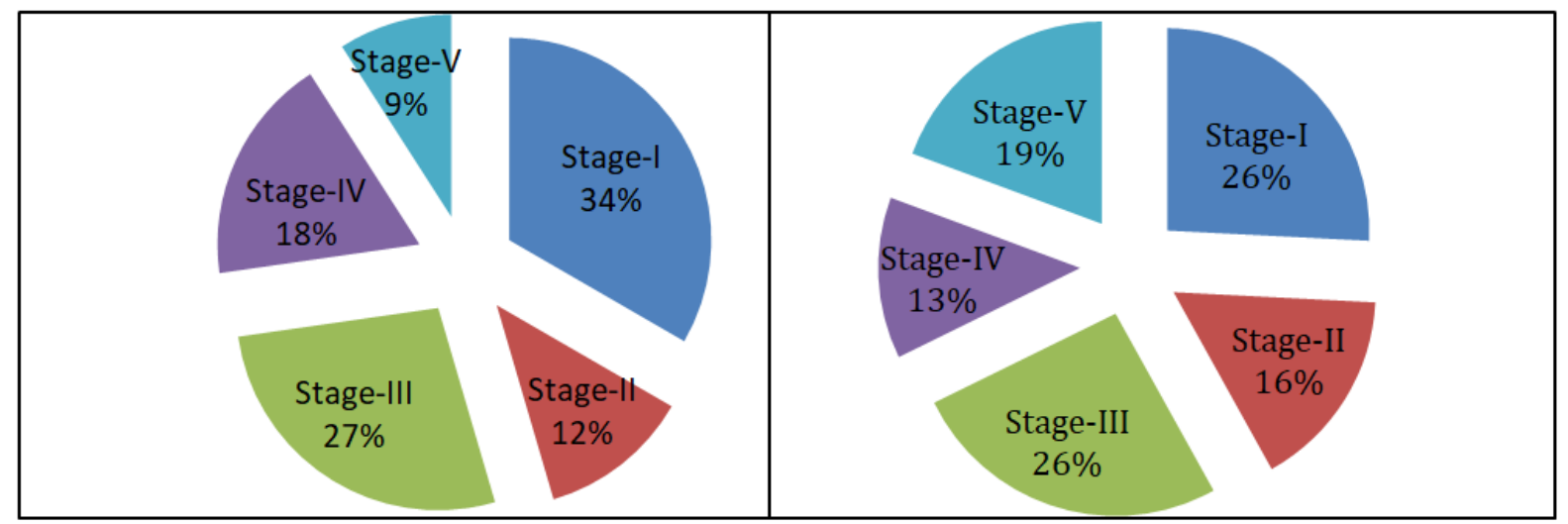

(a)

(b)

Figure 13: The percentage of ovarian development stages of Scylla olivacea from Koyra, Khulna district (a) and from Symnagor, Satkhira district (b), southwestern Bangladesh.

Maturity size: In the present study, the smallest ICW at which females attained a vitellogenic ovary (stages III-V) was $70.8 \mathrm{~mm}$. The frequency of crabs with a vitellogenic ovary increased as the body size increased. The $50 \%$ females attain matured (from stage III-V) at the size of $84.63 \mathrm{~mm} \mathrm{ICW}$ (Figure 14).

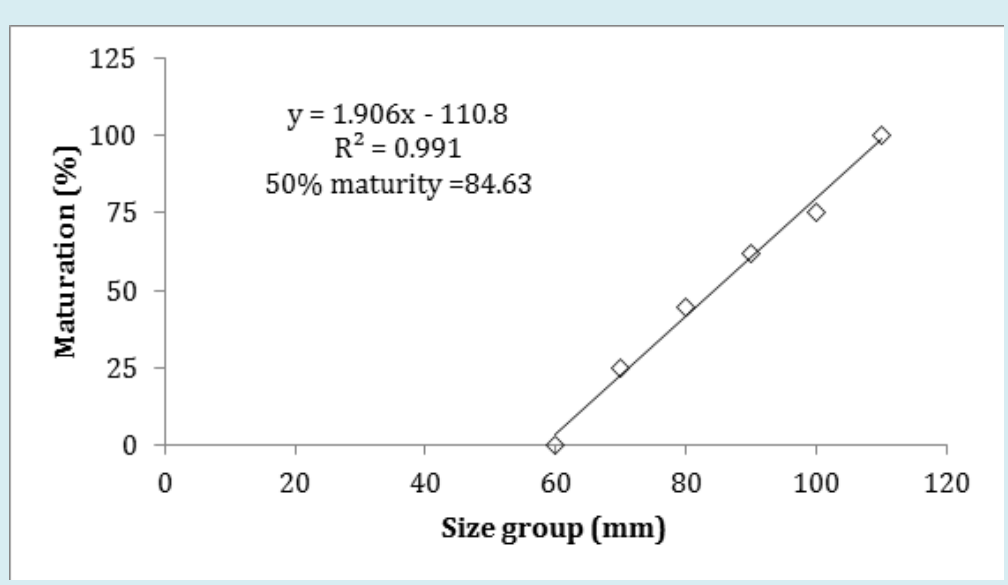

Figure 14: The estimation of 50\% maturation of Scylla olivacea from two coastal districts of Bangladesh at each internal carapace width class (size class $10 \mathrm{~mm}$ ). The $50 \%$ maturity $=84.63 \mathrm{~mm}$.

\section{Discussion}

\section{Relative Abundance}

The estimated average abundance of female crabs was about 40 crabs/day/collector from the study area. The monthly catch size (number of female) was almost similar pattern in both sub-districts. However, a bit higher number recorded during the month of October from Koyra, Khulna where July and August from Symnagor, Satkhira. Though the number of female crabs (including hijra) recorded significantly $(P>0.05)$ higher in Symnagor, the biomass i.e. the catch per unit effort (CPUE in weight) was not significantly differ between two areas. This is due to higher number small size female (hijra) catch from Symnagor area. Since there was no report yet on the abundance of female mud crab (Scylla olivacea) in Bangladesh, the present findings is incomparable. However, single study noticed in the study area and recorded about 482 crabs/ha which represent the average biomass as $28.85 \mathrm{~kg} / \mathrm{ha}$ [17] including all sexes. 
Regardless of the country, other studies like like Dumas, et al. [18] recorded 13.7-19.3 crabs/ha from Voh-Kone area of New Caledonia with the biomass of 9.2-9.9 kg/ha and Nand, et al. [19] reported 2.3-12.5 crabs/ha from Bua Mangrove forest of Fiji. Highest densities were found in Tanzania with $1228 \mathrm{crabs} / \mathrm{ha}$ at the mangrove fringe and $324 \mathrm{crabs} / \mathrm{ha}$ in the inner mangroves, consequential in biomass estimates of 604 and $188 \mathrm{~kg} / \mathrm{ha}$, respectively [20].

\section{Physicochemical Parameter and Distribution of Female Crabs}

Water parameters were not significantly different $(P>0.05)$ among the mean values of the two districts and did not show any significant correlation with the female abundance, recruitment with the water temperature and salinity in both districts. The hijra (immature female) \% was significantly $(P>0.05)$ higher in Symnagor area. Though no significant differences in salinity in two districts but a bit mean higher water salinity in Symnagor area. However, surprisingly higher number of hijra noticed during the months of September to November when Salinity goes down sharply and increased DO. On the other hand, no such results noticed in Koyra area where hijra (\%) did not increased in low salinity time and higher DO. The information on the consequence of physiochemical parameter on the distribution and recruitment of female crabs are lacking. Temperature and salinity are the two of the main environmental parameters that affect mud crab survival, settlement and development. When mud crab turns to first crab stage, the tolerance capacity increased toward lower salinities $[10,21]$. Juveniles (3-99 $\mathrm{mm} \mathrm{CW}$ ) are desire to resident in the upper intertidal of mangrove forest between pneumatophores of Avicennia marina near the mangrove fringe at low tide $[11,22]$. Thus, it may say that may be other physiochemical factors or vegetation pattern or hydrological process may affect the recruitment of female crabs in the Sundarbans mangrove forest of Southwestern Bangladesh.

\section{Breeding Biology}

Female crabs were significantly $(P>0.05)$ higher $(52 \%)$ in Symnagor area rather than Koyra area (46\%). However, overall female was slightly dominant in the region which is supported by Islam (2019) from the same area. Female dominancy also reported from south-east coast of the Bay of Bengal of India [23]. However, male dominancy also reported by others from different places $[18,24]$. The size of crabs recorded ranged 60 to $112 \mathrm{~mm}$ internal carapace width (ICW) which was smaller than other reports like, 50 to $130 \mathrm{~mm}$ ICW reported from Satkhira districts, Bangladesh [17], 40 to $140 \mathrm{~mm}$ CW reported from Klong Ngao mangrove swamps, Ranong Province, Thailand [25], 87-181 mm CW recorded by Dumas, et al. [18] from Voh-Kone area of
New Caledonia. The wide range like 20.8 to $140 \mathrm{~mm} \mathrm{CW}$ reported by Lebata, et al. [26] from Ibajay mangroves, Aklan, Philippines. The size-class distribution showed that the most of the female individuals (33\% and 36\%) were belong to $80-89 \mathrm{~mm}$ ICW from Koyra and Symnagor area respectively. Regardless of the sex, different $(70-79 \mathrm{~mm})$ predominant size-class reported by Islam [17] from the Satkhira district, Bangladesh. However, in 2004 the most individuals recorded in the size-class $81-90 \mathrm{~mm}$ ICW from Khulna region of Bangladesh [2]. The average female size recorded 76.4 \pm 12.3 and $78.6 \pm 15.4$ from Koyra and Satkhira district respectively. Again, regardless of sexes, the average crab size was recorded $82.43 \pm 16.09 \mathrm{~mm}$ ICW from Satkhira district in 2019 [17]. Thus, though present study focused only female crabs, it may say that the population is under pressure as the mean size is declining. The average size also smaller than other such reports like, $134 \mathrm{~mm}$ CW recorded by Dumas, et al. [18] from Voh-Kone area of New Caledonia and $130 \pm 16.09 \mathrm{~mm}$ CW by Nand, et al. [19] from Bua Mangrove forest of Fiji.

The present study investigated ovarian developmental stages of Scylla olivacea on the basis of external observations of the ovary. The general ovarian development features and ovarian developmental stages of $S$. olivacea are similar to Islam, et al. [16] and those of S. serrata [27-29]. In the present study, it was showed that mature female (stage-V) was very few (9 \%) in the sampling area Koyra, Khulna while 19\% individuals were maturation stage (stage- $V$ ) from Symnagor, Satkhira district. However, considering the vitellogenesis i.e. from the stage III-V, almost similar individuals $(54 \%$ and $58 \%$ ) were mature from both areas.

The maturity size of an open water organisms usually denoted as the maturity of the $50 \%$ of their population. In the present research it is showed that the maturity size is $84.63 \mathrm{~mm}$ ICW which is strongly supported by Islam (2019) who recorded $84.98 \mathrm{~mm}$ ICW from Satkhira, Bangladesh. However, delay in maturation also reported from other area, like $95.5 \mathrm{~mm}$ ICW from Klong Ngao mangrove swamps, Ranong Province, Thailand [25] and $99.1 \mathrm{~mm}$ ICW from Pak Phanang mangrove, Thailand [16]. Thus, we can suggest that in the coastal area of Bangladesh, female mud crab should not harvest $<80 \mathrm{~mm}$ ICW.

\section{Conclusion}

The abundance of the female mud crab species of Sundarbans mangrove forest is the first time reported. The female population is getting early maturity and not getting chance to reproduction, hence the population is under threat. The size restriction may imply in the region to manage the female mud crab population. The present findings will provide base line information to manage the female mud crab population. However, it is needed further study to find out 
any strong relationship of female recruitment or breeding pattern regarding other habitat parameters especially the vegetation type and need to consider entire south-western area of the country.

\section{Acknowledgement}

The present study was financially supported by Ministry of Science and Technology, Government of the People's Republic of Bangladesh. I also thanks to the mud crab collectors who supported me by providing samples throughout the year.

\section{References}

1. BEPB (2004) Bangladesh Export Promotion Bureau, Government of the People's Republic of Bangladesh. Dhaka, Bangladesh.

2. Ali MY, Kamal D, Hossain SMM, Azam MA, Sabbir W, et al. (2004) Biological studies of the mud crab, Scylla serrata (Forskål) of the Sundarbans mangrove ecosystem in Khulna region of Bangladesh. Pakistan Journal of Biological Science 7 (11): 1981-87.

3. Islam MS (2018) Mass Engagement of the Local Communities in Mud Crab Culture in the Sundarban Area, Bangladesh: A Potential Livelihood under Threats of Climate Change. Progress in Aqua Farming and Marine Biology 1(1): 180007.

4. Islam MS (2012) Biology and Management of Mud crab fishery in mangrove swamps, Thailand" Lambert Academic Publication, Germany, pp: 85.

5. Robertson WD, Kruger A (1994) Size maturity, mating and spawning in the Portunid crab Scylla serrata (Forska ${ }^{\circ}$ ) in Natal, South Africa. Estuarine Coastal and Shelf Sciences 39(2): 185-200.

6. Arriola FJ (1940) A preliminary study of the life history of Scylla serrata (Forskal). The Phillipine Journal of Science 73: 437-456.

7. Brown IW (1993) Mangrove crabs. In: Wright A, Hill L, (Eds.), Nearshore Marine Resources of the South Pacific. Institute of Pacific Studies (Suva), Forum Fisheries Agency (Honiara) and the International Centre for Ocean Development (Canada) 710: 609-642.

8. Hamasaki K (2003) Effects of temperature on the egg incubation period, survival and developmental period of larvae of the mud crab Scylla serrata (Forskal) (Brachyura: Portunidae) reared in the laboratory, Aquaculture 219(1-4): 561-572.
9. Nurdiani R, Zeng C (2007) Effects of temperature and salinity on the survival and development of mud crab, Scylla serrata (Forsskal), larvae. Aquaculture Research 38(14): 1529-1538.

10. Baylon JC (2010) Effects of salinity and temperature on survival and development of larvae and juveniles of the mud crab, Scylla serrata (Crustacea: Decapoda: Portunidae). Journal of the World Aquaculture Society 41(6): 858-873.

11. Alberts-Hubatsch H, Lee SY, Meynecke J, Karen Diele, Inga Nordhaus, et al. (2016) Life-history, movement, and habitat use of Scylla serrata (Decapoda, Portunidae): current knowledge and future challenges. Hydrobiologia 763: 5-21.

12. Perrine D (1978) The mangrove crab on Ponape. Marine resources division, Ponape, Eastern Caroline Islands marine resources Division, Ponape, Eastern Caroline Is, pp: 66.

13. Ewel KCS, Rowe B, McNaughton, Bonine KM (2009) Characteristics of Scylla spp. (Decapoda: Portunidae) and their mangrove forest habitat in Ngaremeduu Bay, Republic of Palau, Pacific Science 63: 15-26.

14. Chakraborty BK, Azad SA, Sarker S (2018) Present Status of Mud Crab Population in Bangladesh International Journal of Oceanography \& Aquaculture 2(2): 1-11.

15. Abedin M, Shaw R (2014) Safe water adaptability for salinity, arsenic and drought risks in southwest of Bangladesh. Risk Hazards Crisis Public Policy 4(2): 6282.

16. Islam MS, Kodama K, Kurokura H (2010) Ovarian development and size at maturity of the mud crab Scylla olivacea in Pak Phanang mangrove swamps, Thailand. Marine Biology Research 6(5): 503-510.

17. Islam MS (2019) The mud crab fishery of the Sundarbans mangrove of Satkhira district (south-western Bangladesh); biological traits to manage the resource. International Journal of Biosciences 14(5): 357-368.

18. Dumas P, Leopold M, Frotte L, Peignon C (2012) Mud crab ecology encourages site-specific approaches to fishery management. Journal of Sea Research 67(1): 1-9.

19. Nand Y, Fox M, Mangubhai S (2016) A preliminary assessment of mud crab stocks in mangrove forest in Bua province, Fiji. Wildlife Conservation Society, Suva, Fiji, pp: 9.

20. Barnes DKA, Dulvy NK, Priestley SH, Darwall WRT, Choisel V, et al. (2002) Fishery characteristics and 
abundance estimates of the mangrove crab Scylla serrata in Southern Tanzania and Northern Mocambique. South African Journal of Marine Science 24(1): 19-25.

21. Ruscoe IM, Shelley CC, Williams GR (2004) The combined effects of temperature and salinity on growth and survival of juvenile mud crabs (Scylla serrata Forskal). Aquaculture 238(1-4): 239-247.

22. Mirera DO (2014) Capture-based mud crab (Scylla serrata) aquaculture and artisanal fishery in East Africa-Practical and ecological perspectives. PhD thesis, Linnaeus University, Kalmar, Sweden.

23. Kannathasan A, Rajendran K (2011) Sex ratio of the portunidae crab Charybdis natator (Herbst, 1974) from Nagapattinam, south east coast of Bay of Bengal, India. Elixir Biology and Technology 40: 5388-5390.

24. Ikhwanuddin MHD, Azmie G, Juariah HM, Zakaria MZ, Ambak M (2011) Biological information and population features of mud crab, genus Scylla from mangrove areas of Sarawak, Malaysia. Fisheries Research 108(2-3): 817-
820.

25. Jirapunpipat K, Yokota Masashi, Watanabe S (2007) Abundance and size distribution of female Scylla olivacea in Klong Ngao mangrove swamp, Ranong Province, Thailand. La Mer 45(4): 165-175.

26. Lebata MJHL, VayLLe, Primavera JH, Walton ME, Binas JB (2007) Baseline assessment of fisheries for three species of mud crab (Scylla spp.) in the mangroves of Inajay, Aklan, Phillippines. SEAFDEC/AQD 80(3): 891-904.

27. Poovachiranon S (1992) Biological studies of the mud crab Scylla serrata (Forskal) of the mangrove ecosystem in the Andaman Sea. BOBP, Madras (India), pp: 49-57.

28. Onyango SD (2002) The breeding cycle of Scylla serrata (Forskal, 1755) at Ramisi River estuary, Kenya. Wetlands Ecology and Management 10: 257-263.

29. Quinitio ET, De Pedro J, Parado-Estepa FD (2007) Ovarian maturation stages of the mud crab Scylla serrata. Aquaculture Research 38(14): 1434-1441. 